\title{
The uneasy case for lower Parking Standards
}

\author{
W. Bowman Cutter $^{1}$, Sofia F. Franco ${ }^{2}$
}

January 2012

(First Draft)

\begin{abstract}
Minimum parking requirements are the norm for urban and suburban development in the United States (Davidson and Dolnick (2002)). The justification for parking space requirements is that overflow parking will occupy nearby street or off-street parking. Shoup (1999) and Willson (1995) provides cases where there is reason to believe that parking space requirements have forced parcel developers to place more parking than they would in the absence of parking requirements. If the effect of parking minimums is to significantly increase the land area devoted to parking, then the increase in impervious surfaces would likely cause water quality degradation, increased flooding, and decreased groundwater recharge. However, to our knowledge the existing literature does not test the effect of parking minimums on the amount of lot space devoted to parking beyond a few case studies. This paper tests the hypothesis that parking space requirements cause an oversupply of parking by examining the implicit marginal value of land allocated to parking spaces. This is an indirect test of the effects of parking requirements that is similar to Glaeser and Gyourko (2003). A simple theoretical model shows that the marginal value of additional parking to the sale price should be equal to the cost of land plus the cost of parking construction. We estimate the marginal values of parking and lot area with spatial methods using a large data set from the Los Angeles area non-residential property sales and find that for most of the property types the marginal value of parking is significantly below that of the parcel area. This evidence supports the contention that minimum parking requirements significantly increase the amount of parcel area devoted to parking.
\end{abstract}

\section{JEL Codes: R52, H23.}

Keywords: Parking; Land Use; Sprawl

\footnotetext{
${ }^{1}$ Pomona College, Department of Economics, Claremont, CA 91711; Telephone 909-607-8187; Email Bowman.Cutter@Pomona.edu

${ }^{2}$ Corresponding author. Nova School of Business and Economics (Nova SBE), Universidade Nova de Lisboa, Campus de Campolide P-1099-032, Lisboa, Portugal. Email: sfranco@novasbe.pt. Phone: +351-21-380-1600 Ext: 1353. And UECE-Research Unit on Complexity and Economics, Lisboa, Portugal.
} 


\section{Introduction}

Most cities in the US have parking standards which require developers to provide a minimum amount of off-street parking per square foot of floor space. ${ }^{3}$ These minimum parking requirements are usually set by city planners from standardized transportation planning manuals, which typically measure parking and trip generation rates at peak periods with ample free parking and no public transit. The goal of Minimum Parking Requirements (MPRs) is to ensure adequate parking at a low price in order to limit local congestion and to stimulate local business (Shoup (1999)).

Minimum parking requirements have been criticized due to their land and transportation market distortions. Opponents of MPRs (Shoup (1999, 2005), Willson (1995)) argue that these parking standards create an oversupply of parking in most urban areas which decreases the cost (direct and time) of parking and therefore encourages more automobile trips (Shoup (1999, 2005), Shoup and Pickrell (1978)). As the number of cars increase and mass transit use decreases, air quality decreases. Decreased air quality creates and/or aggravates health problems for urban residents. Individuals who suffer from pulmonary diseases such as asthma and bronchitis suffer as the increased number cars decrease air quality (EPA (1999, 2008), Shoup (1999)). In addition, critics allege that minimum parking requirements force developers to use more land space per square foot of building construction and make development in areas where land has a high value much more expensive and less profitable (Willson (1995)). As a result, minimum parking requirements influence the location of new development, make infill projects and historic building retrofits less attractive and feasible (Shoup and Pickrell (1978)) and contribute to the sprawling of impervious parking surface at the expense of the environment (Feitelson and Rotem (2004)) and urban design (Mukhija and Shoup (2006)). However, the previous debate does not consider other factors that may interact with MPRs such as Floor-AreaRatio (FAR) restrictions. A FAR restriction is a density regulation that imposes a restriction on a building's FAR, which equals the total floor area in the building divided by the lot size. A limit on FAR thus prevents a developer from constructing tall buildings.

\footnotetext{
${ }^{3}$ For example, the zoning ordinance for Wilshire Boulevard in Los Angeles requires three parking spaces per 1,000 square feet of gross floor area for office buildings and other commercial uses (Shoup (1999)).
} 
The purposes of this paper are twofold. First, we develop an analytical model of building construction that includes MPRs, FAR restrictions and endogenous decision-making over surface versus below-ground parking. This theoretical model allows us to formally examine the impacts of minimum parking requirements on development density, parking external costs and amount of parking supplied, adding to a small analytical literature on this regulation. And second, we test the hypothesis that parking requirements cause an oversupply of parking using data on commercial, industrial and retail property sales from Los Angeles County.

Even though parking requirements are intensely debated in urban and transport planning arenas, little effort has been devoted to the theoretical analysis of this instrument. The only analytical studies are by Shoup and Pickrell (1978) and Feitelson and Rotem (2004). Both studies use graphical analysis to discuss the impacts of minimum parking requirements on parking price and quantity. Shoup and Pickrell (1978) focus their graphical discussion on how minimum parking requirements may affect the development of parking submarkets. They argue that if parking requirements are uniform throughout a jurisdiction while demand and supply vary by location, the requirements may force an increase in the total amount of parking provided but also an inefficient allocation of parking across space. Feitelson and Rotem (2004) focus their graphical discussion on the external costs of surface parking. The authors argue that even without minimum parking requirements, developers will oversupply parking because of the direct environmental negative externalities and the indirect sprawl-inducement externalities.

There are also some theoretical analyses on the impacts of density zoning on the urban spatial structure and on the urban welfare (Arnott and Mackinnon (1977), Bertaud and Brueckner (2005)). For example, Bertaud and Brueckner (2005) show theoretically that FAR restrictions encourage urban sprawl and increase commuting costs for edge residents of a city. However, we are not aware of any analyses in the zoning literature that also take into account the interaction of FAR restrictions with transportation policies such as MPRs. Both FAR and MPR are land use regulations with impacts on structural densities. FAR restrictions are designed to deal with neighborhood crowding or congestion and regulate how buildings impede each other's view and access to sunlight. MPRs on the other hand are designed to prevent traffic congestion effects and spillover parking effects - parking from a development that overflows into surrounding areasfrom new development. However, because MPRs increase the costs of new development, these policies not only increase the cost of housing but may also reduce density at which developers 
would otherwise be able to build new housing, potentially restricting the supply of new units. Additionally, these minimum standards may also counteract other local policies designed to encourage downtown density to increase agglomeration economies or policies designed to promote development in areas easily accessible by public transit.

One of the advantages of constructing a theoretical model that captures the essence of the problems associated with minimum parking requirements is that such a model can develop and support hypothesis that we can test empirically. Moreover, it also may provide useful insights beyond those provided by earlier papers. For example, parking requirements can influence building density, but may not always be the largest barrier to density. Zoning conditions, in particular FAR restrictions may be a larger barrier in certain cases.

Thus, in contrast to Shoup and Pickrell (1978) and Feitelson and Rotem (2004), we develop a theoretical framework where we model separately the behavior of city center developers and suburban developers and where parking and floor space are bundled and rented as a package to tenants of a building. Both types of developers maximize profits. We extend previous analyses by considering two types of parking structures: underground parking or surface parking. ${ }^{4}$ In our model surface parking also generates negative external environmental costs. Another feature of our model is the presence of a floor-to-area (FAR) restriction. Within this model we examine not only the impact of MPRs on total parking supplied but also on the supply of different types of parking (surface and underground), building square footage and level of parking externality.

Our analytical results show that surface parking is more efficient if the price of land is relatively low. For a sufficiently high price of land, the developer provides underground parking instead of surface parking. Because parking space is capitalized into rents, this will encourage developers to voluntarily supply parking space whenever the resulting revenue will cover its costs, even in the absence of parking requirements. Because developers do not take into account parking external costs, developers will oversupply parking in an unregulated market. The main effects of MPRs are that parking spaces will be priced below the cost of providing them and the external costs associated with surface parking will be exacerbated because MPRs exacerbate the market oversupply of parking. In addition, MPRs constitute an indirect tax on building square

\footnotetext{
${ }^{4}$ We realize that there is also above-ground structure parking that is an intermediate choice between underground and surface parking, but we believe that the underground and surface parking captures the essential elements of the developer’s parking choice problem.
} 
footage which creates a disincentive to high-density development. In particular, minimum parking requirements may drive the total square footage allowed and potentially inhibit density below what a FAR limit permits. ${ }^{5}$ However, in areas with stringent limits on building height and where parking can feasibly be provided, our analytic results suggest that FAR limits may be a more important constraint on densities.

Parking lots occupy a significant proportion of the built cover in many urban and suburban areas. Ferguson (2005) estimates that in multi-family areas parking lots comprise about 30\% of the built cover and in commercial areas parking lots comprise about $60 \%$ of the built cover. Increases in impermeable surfaces such as parking have important environmental consequences because impermeable surfaces are thought to cause a variety of environmental, mainly waterrelated externalities (Arnold and Gibbons (1996)). If the effect of parking minimums is to significantly increase the land area devoted to parking, the increase in impervious surfaces would likely cause water quality degradation, increased flooding, and decreased groundwater recharge. Thus, knowledge of whether or not MPRs are binding is important information.

Shoup (1999) and Willson (1995) provide cases where there is reason to believe that parking requirements have forced developers to place more parking than they would in the absence of this regulation. However, we are not aware of any broad based empirical evidence that tests whether it appears that developers are placing significantly more parking on their land than they would in the absence of parking requirements. In addition, to our knowledge there is also no study that examines which land use categories are most affected by minimum parking requirements.

In this paper we test the hypothesis that parking space requirements cause an oversupply of parking using both direct and indirect approaches. Our direct test compares actual versus required parking for a subsample of our data where we are able to approximate MPRs for the property. Our indirect approach uses the gap between the marginal parking space costs and the marginal value of an additional parking space to the sale price to measure the extent of oversupply of parking. Based on our analytical results, this gap should be zero whenever MPRs are not binding. Therefore, if MPRs bind this wedge should be positive. Our indirect test is thus very similar to Glaeser and Gyourko (2003) who use the gap between real estate prices and the

\footnotetext{
${ }^{5}$ This could occur whenever the amount of parking is constrained for example due to site geometry (size and shape) and/or inconvenient site topography (slopes and poor soil conditions) which substantially increase parking costs.
} 
costs of producing a marginal apartment to measure the distortions in the housing market caused by zoning restrictions on new construction. ${ }^{6}$

We estimate the marginal values of parking and lot area with spatial and non-spatial methods from Los Angeles area non-residential property sales. The data encompass a wide variety of industrial, service, shopping and general retail properties, and office properties from 1997-2005. We use a spatial hedonic approach that includes property and locational characteristics and various controls for spatial dependence.

Significant work has been done using hedonic methods to examine how various attributes affect the sale price of non-residential parcels. Most of this work relates to the determinants of commercial property sale indices. ${ }^{7}$ This literature considers a variety of locational, neighborhood, building and parcel characteristics, but we are only aware of one previous study that considers the amount of parking on the property (Cutter and DeWoody (2010)). In addition, other work attempts to value environmental disamenities by examining whether property prices change in response to the listing or de-listing of hazardous waste sites near a property (Ihlanfeldt and Taylor (2004)). We use a spatial hedonic approach where parking area, a characteristic that has only been included in Cutter et al. (2010), is one of the characteristics of the property.

Our empirical results find that the marginal value of parking on a lot appears to be significantly less than the marginal value of parcel area in several land-use categories in all specifications. The difference between the marginal parking and marginal property area values is significant and supports the contention that minimum parking space requirements substantially increase the amount of parcel area allocated to parking by developers. Our direct test of whether

\footnotetext{
${ }^{6}$ The authors provide evidence that zoning is in fact constraining the supply of housing in a number of housing markets across the United States. Glaeser and Gyourko (2005) emphasize that there is no reason why housing prices cannot fall below construction costs in declining areas. In those areas, there will be no construction and any regulation that place limits on residential building would not bind.

7 Some examples are Hodgson et al. (2006) and Colwell et al. (1998). Other empirical studies have examined demand side and supply side influences on office-commercial rents. Clapp (1980) tested the rent-accessibility tradeoff using 105 office buildings data in Los Angeles and found significant evidence to support the negative rental function with respects to the distance from the CBD and the commuting time. His results also supported the importance of face-to-face interaction in the CBD. Using a more recent set of office rental data in Greater Los Angeles from the same source, Sivitanidou (1995) again found that the accessibility factors (distance to CBD, distance to airport and number of interstate freeways) are significantly reflected in variations of the office rental function. However, the author found that the standard bid-rent function is incomplete in explaining office bid-rent relationships unless other variables like worker amenities, zoning and local institutional control are included in the model. Sivitanidou (1996) shows that office-commercial firms value access to service centers within Los Angeles PMSA (Primary Metropolitan Statistical Area). None of these previous studies examine how parking area influences office-commercial bid rent functions.
} 
MPRs bind, which uses a subsample of office properties, shows also that properties tend to have just the minimum parking requirement or somewhat less parking than required.

The plan of the paper is as follows. Section 2 provides the regulatory background for Minimum Parking Requirements and describes the environmental impacts associated with conventional parking lots. Section 3 outlines the theoretical model and examines the impacts of minimum parking requirements on the supply of surface parking, supply of underground parking, building density and level of parking externalities. Section 4 develops the empirical model. Section 5 describes our data and variables. Section 6 discusses our parking regulation tests. Section 7 presents the empirical results and discusses their implications and finally, Section 8 offers conclusions.

\section{Regulatory and Environmental Background}

\subsection{Minimum Parking Requirements}

The minimum parking requirements for cities in the Los Angeles area are Byzantine in their complexity. ${ }^{8}$ Parking requirements can differ significantly across property types that would seem similar to the uninitiated. The basis also can differ. Many requirements are expressed as numbers of parking spaces per square foot of gross building floor area, but other depend on adjusted gross area, number of employees, number of seats in a restaurant, and other more complex ratios. In addition, cities often have different zones where different parking requirements apply. Finally, projects can be granted variances from general MPRs. For all these reasons, a direct approach to estimating the effect of parking minimums on the amount of parking space, such as regressing parking area on the parking minimum and controls, faces serious obstacles because it would be very difficult to know what MPR applies to a property.

This point is reinforced by our data analysis. We analyze data for a subsample of properties (office buildings in certain cities) where the current MPR requirements were only based on square footage of the building and examined the ratio of actual to required parking spaces. We found the mean ratio is .97 , indicating that these buildings usually have close but slightly less parking than required. However, many buildings have many fewer than the required number of spaces in current regulation. The $25^{\text {th }}$ percentile of actual to required spaces is .72 , so $25 \%$ of

\footnotetext{
${ }^{8}$ For instance, the Santa Monica requirement for health clubs is " 1 space per 80 sq. ft. of exercise area, 1 space per each 300 sq. ft. of locker room/sauna/ shower area, plus applicable code requirement for other uses.”
} 
properties have less than $72 \%$ of the required spaces. This could either be the result of not having the exact parking requirements at the time of construction or widespread exceptions (variances) allowing less than the MPR.

If widespread variances exist, then it could be that, while in theory MPRs produce inefficient outcomes, in practice local authorities consider the costs and benefits for MPRs and grant variances where costs of compliance are particularly high and by doing this they reduce the social cost of MPRs. Shoup (2005) states that many municipalities rely on the Institute of Transportation Engineers (ITE) parking generation rate studies, and in particular their maximum generation rate ${ }^{9}$, to set minimum parking standards. However, our data raises the possibility that the actual requirements for projects can be lower than the regulatory standards criticized by Shoup (2005). This is similar to the common finding in the environmental regulatory literature that local regulators adjust regulations for the costs and benefits of pollution control at a particular facility (Gray and Deily (1991)). Our indirect method avoids the pitfall of assuming that MPRs apply uniformly and tests whether parking requirements, as they are actually applied, result in economic distortions.

\subsection{Environmental Costs of Parking}

Parking lots degrade air and water quality (Akbari et al. (2001)), decrease the amount of greenspaces, increase urban heat island effects, and can decrease water supply (Cutter et al. (2008)). These negative environmental externalities will differ in their magnitude from place to place.

The water-related externalities are generated because parking lots are impervious to water and moisture and therefore cause more rainfall to flow off the surface as runoff. This decreases water supplies as groundwater aquifers are not recharged and decreases surface water quality as the runoff tends to accumulate oil, grease, and other pollutants from the pavement. Cutter et al. (2008) estimates that an additional acre of impervious surface can decrease annual infiltration

\footnotetext{
${ }^{9}$ These figures are based on studies where a land use category is observed over several days to several weeks and the maximum observed parking spaces over that period of time is designated as the maximum parking generation rate. I.e. if a shopping center were observed over five weekdays and the maximum occupied parking spaces over that period was 300 , that would be the maximum parking generation rate for that observation. Then the average of those maximum parking generation rates (usually per square foot) is the maximum parking generation rate for that land-use category.
} 
and recharge to groundwater supplies by 1.1 acre-feet per year with a present value loss of $\$ 16,400$ in water value.

Pollutant air emissions also occur through the lifecycle of a parking lot (EPA (2008)). Asphalt cement plants emit particulate matter, nitrogen oxides, sulfur oxides, carbon monoxide and carbon dioxide during the manufacturing process. The activities associated with construction and maintenance of parking lots also generate emissions in the form of dust, fumes and equipment and vehicle exhaust. The after effects of parking lot construction, such as fewer trees and less vegetation due to clearing also lead to higher amounts of carbon dioxide in the air.

In addition, parking is generally constructed of dark asphalt that, together with other built up dark surfaces generates an urban heat island effect. Akbari et al. (2001) estimates that the urban heat island effect in Los Angeles increases power consumption by 1-1.5 GW at a cost of $\$ 100$ million per year. Also, the higher temperatures due to the urban heat island effect increases ozone (smog) production. Taha (2008a,b) shows that replacement of low-albedo surfaces such as parking with vegetation can result in significant decreases in ozone levels

\section{The Analytical Model}

This section describes the features of the analytical model we will use to examine the impacts of minimum parking requirements on structural density, amount of land developed and type of parking supplied. We also provide and interpret key equations associated with the developers' problem in the absence and presence of minimum parking requirements. Complete derivations are provided in Appendix A.

\subsection{Model Assumptions}

\section{Office-Commercial Rents}

Suppose that the office-commercial-space bid rent in a given location is represented by: ${ }^{10}$

\footnotetext{
10 The office-commercial bid rent represents the maximum willingness-to-pay by a firm for commercial-office space in a building at particular location within the city. In this paper we focus on the behavior of developers and therefore, we do not derive analytically equation (1). However, a demand model for office space, see for example Sivitanidou and Wheaton (1992), would suggest that the quantity demanded is a function of rent, a firm's output, and the amount of office space it uses per worker. If the output market is competitive, in the long-run a firm's profit is zero. From this latter condition we can thus determine the equilibrium rent per unit of floor space (1). Moreover,
} 


$$
B=f(N, A)
$$

where, $B$ is the office-commercial rent per unit of floor space, $N$ is total parking spaces and $A$ represents a vector of amenities associated with the location. Equation (1) thus suggests that parking spaces are capitalized into bid rents ${ }^{11}$. Because we focus on a single location the value of $A$ is fixed. We assume that (1) is concave in its arguments.

Parking space can take two forms: surface parking and underground parking. Surface parking refers to lots directly on land and underground parking consists of structured parking under multi-story buildings. ${ }^{12}$ Both forms are assumed to be perfect substitutes from the tenants' perspective and therefore, total parking spaces are represented by:

$$
N=N_{s}+N_{u}
$$

where $N_{s}$ is number of surface parking spaces and $N_{u}$ is number of underground parking spaces.

\section{Building Technology}

Office-commercial floor space is produced according to a strictly concave, constant-returns production function, $H=f(K, L)$, where $K$ is capital used to produce floor space and $L$ is the amount of land physically covered by $K$ (referred to subsequently as “covered land”). The intensive form of this production function is written as $h(S)$, where $S$ is capital per unit of covered land or structural density and $h$ satisfies $h^{\prime}>0$ and $h^{\prime \prime}<0 . h(S)$ represents officecommercial total floor space per unit of covered land. We assume that $L$ is fixed.

for simplicity, we assume that bid rents reflect prevailing market prices for office floor space, so that the two are synonymous. Thus, the price of an office building would be the product of the bid-rent and total office floor space.

${ }^{11}$ Building characteristics can influence the bid rent for office-commercial space at a particular location. Rents are higher for buildings with greater total square footage, more floors and parking space. A higher total square footage may be also indicative of building amenities (e.g. restaurants), face-to-face agglomeration economies or shopping externalities. Office-commercial bid rents are also influenced by locational factors such access to the central business district, access to surface and air transportation (freeways and major airports), access to good schools and level of crime. For empirical evidence on the determinants of office-commercial bid rents see Sivitanidou (1995) and Bollinger et al. (1998).

${ }^{12}$ Other types of parking facilities include on-street parking, off-street parking and structured parking in multistory buildings. On-street parking consists of parking lanes provided within public road rights-of-way. Off-street parking are parking facilities on their own land, not on road rights-of-way. Structured parking (also called parkades or ramps) are parking facilities in or under multistory buildings. It is not uncommon to find structured parking in downtown areas since land costs are very high. For simplicity we only analyze the cases of surface and underground parking (structured parking under multi-story buildings). However, our results on underground parking can also be extended to other types of structured parking. 


\section{Parking Costs}

Parking costs differ depending on the type of parking facility provided. Construction costs (excluding land) per space of surface parking are lower than the construction costs per space for underground parking (Hunnicutt (1982)). ${ }^{13}$ However, surface parking precludes alternative uses of land and hence its total costs are the sum of total construction costs and land costs $\left(C_{s}\left(N_{s}\right)\right)$ :

$$
C_{s}\left(N_{s}\right)=N_{s}\left(p_{k} \bar{K}+p_{l} \bar{l}\right)
$$

where $p_{l}$ and $p_{k}$ are the exogenous prices of land and capital, $\bar{K}$ is the fixed amount of capital per surface parking space and $\bar{l}$ is the fixed amount of land per surface parking space.

We assume that no additional land is necessary for underground parking since it will be built below the office-commercial building. Therefore, total costs for underground parking reflects mainly its construction costs:

$$
C_{u}\left(N_{u}, S\right)=N_{u} p_{k} K\left(N_{u}, S\right)
$$

where $K\left(N_{u}\right)$ is the capital cost requirement per underground parking space and is assumed to be a convex function with $\frac{\partial^{2} K\left(N_{u}, S\right)}{\partial N_{u} \partial S}>0$. The reason is because as more underground parking is added more units of capital are necessary to fortify the building structure and to provide vertical-transportation requirements.

\section{Surface Parking Externalities}

Surface parking generates multiple environmental externalities. Let $L_{S}$ be the amount of impervious land due to surface parking and $E\left(L_{s}\right)$ denote the external costs associated with impervious surfaces. We assume that $E\left(L_{s}\right)$ is linear in the amount of land allocated to surface parking:

$$
E\left(L_{s}\right)=e L_{s}
$$

where $e>0$ is the unit of land external cost and $L_{s}=N_{s} \bar{l}$.

\section{Parking Requirements}

\footnotetext{
${ }^{13}$ Construction costs (excluding land) average about $\$ 1,600$ per space for surface parking and $\$ 20,000$ or more per space for underground parking (Hunnicutt (1982)).
} 
The city government imposes a minimum parking requirement expressed as numbers of parking spaces per square foot of gross building floor area:

$$
N \geq a \operatorname{Lh}(S)
$$

where $0<a<1$ is a parameter imposed by the city government. ${ }^{14}$

\section{Floor-Area-Ratio (FAR) restrictions}

There is also an upper limit on the square footage of office-commercial space per unit of land such that:

$$
h(S) \leq \hat{h}(\hat{S})
$$

where $\hat{h}$ is the FAR limit per unit of land and $\hat{S}$ is the total structural density associated with $\hat{h}$.

\subsection{Type of parking provided}

Differentiating (1) with respect to $N_{s}$ and $N_{u}$, yields the same marginal benefit for both types of parking spaces:

$$
\frac{\partial B(N, A)}{\partial N} \frac{\partial N}{\partial N_{s}}=\frac{\partial B(N, A)}{\partial N} \frac{\partial N}{\partial N_{u}}
$$

As a result, the developer determines which type of parking space will be provided based on the marginal cost. The private marginal cost per space of underground parking is given by:

$$
p_{k} \bar{K}+p_{k} N_{u} \frac{\partial K\left(N_{u}, S\right)}{\partial N_{u}}
$$

The first component of (9) is the marginal cost for the additional underground parking space, which is the same for all parking spaces in the structure. The second component of (9) is the inframarginal cost associated with the additional underground space. Note that the marginal cost of underground parking increases with the height of the building because of the costs of providing vertical transport and supporting a heavier building.

\footnotetext{
${ }^{14}$ Note that $H(K, L)=L h(S)$. Since $H(K, L)$ is concave and homogenous of degree one, it follows that $H(K / L, 1)=h(S)$. Also, the value of $a$ can be lower, equal or higher than the value of $a$ that would exist in an unconstrained market. However, for the purpose of exploring the effects of minimum parking requirements we consider the case where $a$ is such that the constraint is always binding and thus, affects the market equilibrium. If for example, $a=1 / 200 \mathrm{sft}$, it means that developers are required to provide one parking space for each 200sft of gross floor area.
} 
The private marginal cost per space of surface parking is given by:

$$
p_{k} \bar{K}+p_{l} \bar{l}
$$

The first component of (10) is the marginal cost for the additional surface parking space and the second component is the marginal cost of land. In contrast to (9), the marginal cost of surface parking is constant and thus, it does not vary with the amount of parking space.

Comparing (9) and (10), the marginal cost of underground parking is greater than the marginal cost of surface parking if the cost of land is small relative to the degree of diminishing marginal returns:

$$
p_{k} N_{u} \frac{\partial K\left(N_{u}, S\right)}{\partial N_{u}}>p_{l} \bar{l}
$$

Equation (11) suggests that surface parking is more efficient if the price of land is relatively low. ${ }^{15}$ For a sufficiently high price of land, the developer provides underground parking instead of surface parking. ${ }^{16}$ Given that land prices are typically very high in downtown areas, it is not surprising that most parking bundled with office-commercial development in Central Business Districts (CBD) is structured parking. In contrast, low-density office-commercial structures with large surface parking lots such as shopping malls are mostly found in suburban areas where the price of land is lower.

Next we specify the developer's problem separately for the suburbs and the central city taking into account the FAR restriction and Minimum Parking Requirements (MPRs). ${ }^{17}$ Given

\footnotetext{
${ }^{15}$ Structured parking typically becomes cost effective when land prices exceed about $\$ 1$ million per acre.

${ }^{16}$ If the marginal benefit of underground parking exceeds the marginal benefit of surface parking because of differences in the costs and speeds of walking and elevator travel, then the developer may provide underground parking even if the price of land is relatively low:

$$
\frac{\partial B}{\partial N} h(S)\left[\frac{\partial N}{\partial N_{u}}-\frac{\partial N}{\partial N_{S}}\right]>p_{k} N_{u} \frac{\partial K\left(N_{u}, S\right)}{\partial N_{u}}-p_{l} \bar{l}
$$

If $\frac{\partial N}{\partial N_{u}}-\frac{\partial N}{\partial N_{S}}$ is large enough to offset the diminishing marginal returns from underground parking, then underground parking will be provided. Note also that a developer could choose a combination of surface and underground parking spaces that minimizes total costs of providing parking spaces. However, in this paper we focus only on boundary solutions and we assume that a developer can only provide underground or surface parking spaces, but not both types.

${ }^{17}$ In addition to these land use regulations, other parking and zoning policies may be in place that may influence the supplies of parking and office-commercial floor-area. Such additional parking policies include shared parking, sitespecific reductions and cash in lieu. Among non-FAR limitations on building size and form are set-back requirements, open space requirements, height limits and bulk regulations, which require minimum sky exposure to the street. Because an analysis of the interactions between all these policies and FAR and MPR regulations would be very cumbersome without adding to the discussion, we do not address them in our analysis. We hope to revisit some of these limitations in future research.
} 
the preceding discussion, we assume that CBD developers provide underground parking and suburban developers provide surface parking.

\subsection{Central Business District (CBD)}

The developer's problem in the central city is to choose the level of structural density and number of underground parking spaces that maximize his profits per unit of covered land taking into account the FAR restriction and MPRs: ${ }^{18}$

$$
\begin{aligned}
& \underset{N_{u}, S}{\operatorname{Max}} B\left(N_{u}, A\right) h(S)-p_{k} S-p_{l}-p_{k} N_{u} K\left(N_{u}, S\right) \\
& \text { s.t. } h(S) \leq h(\hat{S}) \\
& N_{u} \geq a L h(S)
\end{aligned}
$$

For the sake of expository convenience, we represent the Kuhn-Tucker conditions for an interior solution for problem (12) in Table 1, where $\lambda_{1}$ is the shadow price associated with the FAR constraint and $\lambda_{2}$ is the shadow price associated with the MPR constraint. ${ }^{19}$ All the firstorder conditions are evaluated at the optimum levels. For full details see Appendix A.

There are three main conclusions that we can take upon examining table 1 . First, because parking is capitalized into office-commercial rents, this will encourage developers to voluntarily supply parking whenever the resulting revenue will cover its costs, even in the absence of MPRs $\left(\left(\lambda_{1}=0, \lambda_{2}=0\right)\right.$ and $\left.\left(\lambda_{1}>0, \lambda_{2}=0\right)\right)$. If the price of additional underground parking $\left(\frac{\partial B\left(N_{u}^{*}, A\right)}{\partial N_{u}} h\left(S^{*}\right)\right)$ is at or above the marginal cost of providing it $\left(\frac{\partial C_{u}\left(N_{u}^{*}, S^{*}\right)}{\partial N_{u}}\right)$, there is no

\footnotetext{
${ }^{18}$ Equation (12) also implies that total floor space and parking space are "bundled" and rented as a package to the tenants of a building. For example, in nearly all buildings in Los Angeles today, parking is included in the price or rent of the unit. Tenants do not have the option of "unbundling" the cost of parking from their purchase or rent. The main exception is in the Downtown area where some buildings do not include parking in their rental rates.

${ }^{19}$ This shadow price (the Lagrange multiplier) provides a measure of how a relaxation in the constraint will affect the developer's profit per unit of covered land. Thus, a high value of $\lambda_{i}$ indicates that the profit per unit of land could be increased substantially by relaxing the constraint. In contrast, a low value of $\lambda_{i}$ indicates that there is not much to be gained by relaxing the constraint. When $\lambda_{i}=0$, the constraint is not binding.
} 
reason why developers would not provide it on their own in downtown areas $\left(N_{u}^{*}>0\right)$. Thus, even in the absence of MPRs, developers can offer a bundle of (parking spaces, floor space) as a strategy to maximize profits. ${ }^{20}$ The main effects of MPRs (see both cases where $\lambda_{2}>0$ ) are that parking spaces will be priced below the cost of providing them (for example $\left.\frac{\partial C_{u}\left(N_{u}^{m p r}, S^{m p r}\right)}{\partial N_{u}}>\frac{\partial B\left(N_{u}^{m p r}, A\right)}{\partial N_{u}} h\left(S^{m p r}\right)\right)$ and total supply of parking will be above its market determined equilibrium level $\left(N_{u}^{m p r}>N_{u}^{*}\right)$.

Second, parking requirements may also cause serious problems in the office-commercial floor space market. When MPRs bind $\left(\lambda_{2}>0\right)$, the excess underground parking results in a deficit for the developer of a new building. This induced deficit constitutes an indirect tax on building square footage $\left(\frac{\lambda_{2} L}{N_{u}^{m p r}} \frac{\partial h\left(S^{m p r}\right)}{\partial S}>0\right)$. As a result, this creates a disincentive to highdensity development $\left(S^{*}>S^{m p r}\right)$ because it imposes an extra wedge between the marginal revenue gain from additional building square footage $\left(B\left(N_{u}^{m p r}, \bar{q}, A\right) \frac{\partial h\left(S^{m p r}\right)}{\partial S}\right)$ and the marginal construction costs $\left(p_{k}+\frac{\partial C_{u}\left(N_{u}, \hat{S}\right)}{\partial S}\right)$. Since the marginal cost of providing more parking spaces at a site usually increases dramatically for underground structures $\left(\frac{\partial^{2} C_{u}\left(N_{u}, S\right)}{\partial N_{u}^{2}}>0, \frac{\partial^{2} C_{u}\left(N_{u}, S\right)}{\partial N_{u} \partial S}>0\right)$, this parking tax is also higher for larger buildings.

Finally, FAR restrictions also constitute a tax on building square footage which leads to building heights smaller than those in unconstrained markets $\left(S^{*}>S^{F A R}\right)$. Based on current construction costs, a developer might want to build a taller structure than allowed by density controls and provide the requisite parking in order to maximize returns, even in the absence of parking requirements $\left(\lambda_{1}>0, \lambda_{2}=0\right)$.

Minimum parking requirements may nevertheless drive the total square footage allowed and potentially inhibit density below what the FAR limit permits, in particular when the amount of

\footnotetext{
${ }^{20}$ In this paper, decisions to bundle parking into rents are freely-made private decisions, not forced by excessive parking requirements. Thus, even in the absence of MPRs, bundling of parking remains persistent. A possible reason that may prompt developers to bundle parking is the absence of priced parking nearby. Examining underlying causes of persisting bundling is outside the scope of this study.
} 
parking is constrained due to site geometry (size and shape) and site topography (slopes and poor soil conditions). Site geometry and site topology may make the required parking not physically fit on to a site and increase substantially parking costs and thus, $\lambda_{2}$. In this situation $\lambda_{1}^{F A R} \frac{\partial h(\hat{S})}{\partial S}$ may be smaller than $\frac{\lambda_{2}^{m p r} L}{N_{u}^{m p r}} \frac{\partial h\left(S^{m p r}\right)}{\partial S}$ and thus, $\hat{S}>S^{m p r}$. However, in areas with stringent limits on building height and where parking can feasibly be provided underground, parking requirements may not be the greatest constraint on densities. When both regulatory restrictions bind ( $\left.\lambda_{1}=0, \lambda_{2}=0\right)$, it may be the case that the FAR limit pushes densities further down than MPR.

Our results thus show that minimum parking requirements have counterproductive results in downtown areas because they try to solve a problem in the transportation market that is only indirectly related to the office-commercial floor space market. Because minimum parking requirements increase the costs of new development, these minimum standards tend to decrease the potential office-commercial density of new projects which is counter the objective of most cities to promote downtown density to increase agglomeration economies and control for urban sprawl. In addition, minimum parking requirements may also counteract other local policies designed to encourage development in areas easily accessible by public transit as well as compromise the feasibility of mass-transit investments in certain downtown areas.

\subsection{Suburban Areas}

The developer's problem in the suburbs is to choose the level of structural density and number of surface parking spaces that maximizes his profits per unit of land covered taking into account the FAR restriction and Minimum Parking Requirements (MPRs):

$$
\begin{aligned}
\underset{N_{S}, S}{\operatorname{Max}} & B\left(N_{S}, A\right) h(S)-p_{k} S-p_{l}-\frac{N_{S}}{L}\left(p_{l} \bar{l}+p_{k} \bar{K}\right) \\
\text { s.t. } & h(S) \leq h(\hat{S}) \\
& N_{S} \geq a L h(S)
\end{aligned}
$$

Since the capital-to-land ratio tends to decrease with distance from a CBD, it follows that a FAR restriction will bind in the central part of a city, where the capital-to-land ratio would normally be high, being nonbinding farther from the center (Bertaud and Brueckner (2005)). Thus, we focus our discussion on the cases where only the MPR restriction is binding. The 
Kuhn-Tucker conditions for an interior solution for problem (13) when the FAR restriction is not binding are presented in Table 2. Again, $\lambda_{1}$ represents the shadow price associated with the FAR constraint and $\lambda_{2}$ is the shadow price associated with the MPR constraint. All first order conditions are evaluated at the optimum. For full details see Appendix A.

Parking supply imposes the negative externalities discussed in Section 2. Upon examining Table 2, it is clear that whenever private decisions do not take into account these negative externalities, too much surface parking is provided even in the absence of MPR. ${ }^{21}$

Notice that the socially optimal number of surface parking spaces maximizes $\pi_{s}+\frac{e N_{s} \bar{l}}{L}$, where $\pi_{s}$ is profit per unit of land covered. The first order condition for the social optimal surface parking spaces, $N_{s}^{o}$, is given by:

$$
\frac{\partial B\left(N_{s}, A\right)}{\partial N_{s}} h(S)=\frac{\left(p_{l}+e\right) \bar{l}+p_{k} \bar{K}}{L}
$$

Comparing (14) and the first order condition in absence of regulatory constraints $\left(\lambda_{1}=0\right.$ and $\lambda_{2}=0$ ) one notices that because of the negative externalities associated with impervious surface, the social marginal cost of surface parking $\left(\frac{\left(p_{l}+e\right) \bar{l}+p_{k} \bar{K}}{L}\right)$ is higher than the private marginal cost $\left(\frac{p_{l} \bar{l}+p_{k} \bar{K}}{L}\right)$. As a result, the socially efficient amount of land in surface parking $\left(\bar{l} N_{s}^{o}\right)$ is less than the privately optimal amount $\left(\bar{l} N_{s}^{*}\right)$. Thus, if left to the market the supply of surface parking is likely to be excessive. ${ }^{22}$ Not only are socially beneficial uses of surface

\footnotetext{
${ }^{21}$ Our argument ignores the free rider congestion effect. The free rider problem with respect to private downtown parking provision is a potentially serious one and is the justification for MPRs in the first place. Therefore, one would need to consider this explicitly before claiming that too much land is allocated to surface parking. However, to the extent that most parking in downtown areas is underground and our surface parking analysis is related to suburban areas where this problem is not so severe, we have decided not to model this effect in our suburban developer problem since it would make the analysis cumbersome without additional insights. Moreover, Cutter and DeWoody (2010) indicates that, to the extent congestion effects are capitalized into real estate values, the externalities are only significant for commercial parking garages and are not large for on-site private parking.

${ }^{22}$ Government can encourage the social amount of both surface and underground parking through the imposition of a Pigouvian tax, where the magnitude of the tax is set equal to the marginal external effect at the efficient allocation. This would require imposition of a per unit tax on surface parking, where the magnitude of the tax is set equal to the dollar value of the environmental external costs. Alternatively, the government can also set a maximum parking requirement for surface parking, where the requirement would be equal to the social optimum. However, even if markets should be able to provide about the right amount of parking, there are inadequate economic incentives for quality, although planners could address some of the concerns over the quality of parking by requiring better design of lots and parking structures (Mukhija and Shoup (2006)).
} 
parking land foregone, but because land is paved, it also increases storm water runoff and has other negative environmental impacts.

In the context of the monocentric city model, the spatial area of the city can be found by adding total land in office-commercial use and total land in surface parking. Given that $\bar{l} N_{S}^{O}<\bar{l} N_{S}^{*}$ the market equilibrium is characterized by inefficient spatial expansion of the urban area, providing a basis also for criticism of urban sprawl. ${ }^{23}$

Like in downtown areas, MPRs also enforce an oversupply of parking in suburban areas $\left(N_{S}^{m p r}>N_{S}^{*}\right)$ which, intensifies the external costs associated with impervious surface coverage: $e \bar{l} N_{s}^{m p r}>e \bar{l} N_{s}^{*}>e \bar{l} N_{s}^{o}$. Because minimum parking requirements increase the cost of development, densities are also lower in suburban areas compared to the unconstraint market outcome $\left(S^{*}>S^{m p r}\right)$.

Note that in equilibrium, the shadow price associated with the MPRs satisfies:

$$
\left[p_{l} \bar{l}+p_{k} \bar{K}-\frac{\partial B\left(N_{S}^{m p r}, A\right)}{\partial N_{S}} \operatorname{Lh}\left(S^{m p r}\right)\right] a^{2} h\left(S^{m p r}\right)=\lambda_{2}^{m p r}
$$

From (15) land uses that have higher parking requirements such as retail versus warehouses and thus have a higher value of $a$, are expected to have also a higher shadow price, $\lambda_{2}$. Moreover, if MPRs do not bind ( $\lambda_{2}=0$ ), then the marginal value of parking should be equal to the marginal value of additional land plus marginal parking construction costs. If parking constraints bind, the marginal parking use value should be less than the land value plus construction costs $\left(\lambda_{2}>0\right)$.

\subsection{Testable Hypothesis}

The predicted theoretical relationships between marginal parking use value, marginal land value, and marginal building area value give us the testable hypotheses for the empirical portion of the paper. With proper data, we can estimate the shadow price associated with MPR and make inferences about the underlying equilibrium. For example, in the case of surface parking, the shadow price can be calculated with equation (15). Calculating the extensive margin value of land is simple once we have the construction cost data and the parking requirements data. However, the additional value of a property from adding an additional parking space cannot be

\footnotetext{
${ }^{23}$ Other causes of urban sprawl can be found in Brueckner (2000) and Bento, Franco and Kaffine (2006).
} 
calculated explicitly. It must be inferred using hedonic regression techniques to estimate the marginal contribution of each type of parking space to the price of the office-commercial building.

Our model also implies that the marginal revenue from additional building area should equal marginal construction costs in the absence of binding parking requirements, but be greater than marginal construction costs if parking constraints bind. We do not test this second hypothesis in the present version of this paper, but may examine it in the future.

\section{The Empirical Model}

The empirical part of this paper focuses on the office-commercial-industrial property market within suburban areas of Los Angeles and on surface parking lots. The suburban market was chosen because, as our analytical results suggest, in downtown areas FAR restrictions are likely to bind which in turn can influence development density and the amount of land allocated to surface parking and parking density per acre. ${ }^{24}$ Moreover, surface parking in downtown LA also results from a speculative decision process. ${ }^{25}$ Therefore, isolating the effect of MPR on the amount of land allocated to parking in the built-up areas of Los Angeles may be tricky. In further research we hope to investigate the claims by critics that parking restrictions in fact prevent developers from attaining the maximum FAR. In addition, our analytical results also suggest that surface parking is more efficient if the price of land is relatively low. Given that land prices are typically lower in the suburbs compared to downtown areas it is not surprising that most surface parking occurs in the outskirts of the city.

\footnotetext{
${ }^{24}$ In some cases, zoning regulations include bonus programs that permit developers to exceed the base maximum FAR if they include certain amenities such as affordable housing.

${ }^{25}$ Landowners may face uncertainty that increases the value of waiting to develop the parcel or may anticipate higher profits from developing at a later date. If future needs are uncertain and land use is not easily adaptable (because the developed structure is durable), it may maximize the landowner's return to keep land undeveloped or underdeveloped (for example developed with a cheap land use such as surface parking that allows land to be put to some current use without requiring significant demolition costs in the future) and reserve it for the more highly valued future use than to develop it today. The landowner who keeps land or development capacity off the market is thus taking an option on future development. It has been shown that uncertainty results in a price premium for vacant or underused land (after accounting for demolition costs) and/or that it reduces current development, suggesting that investors recognize the value of real options in real estate development (Sivitanidou and Sivitanides (2000), Cunningham (2006), Grenadier (1996), Holland et al. (2000)). It is also possible that underused land in downtown LA is due to institutional or regulatory barriers and not just landowners' calculation of expected returns. Zoning ordinances, building codes and historic preservation obligations may keep land from being developed.
} 
We estimate the marginal values of parking and lot area with spatial and non-spatial methods from Los Angeles area non-residential property sales. In order to simulate the marginal on-site parking and parcel values we estimate a spatial error model for different land-use categories because parking requirements often differ across land use types (ITE 1985.)

\subsection{Hedonic Price Model}

The bid-rent function given by (1) is the starting point for our hedonic price function specification. This equation implies that office-commercial buildings can largely be considered as bundles of attributes that cannot easily be repackaged to suit individual preferences. The attributes typically evaluated by buyers in the housing market include not only structural characteristics of the properties, but also neighborhood attributes linked to the properties. ${ }^{26}$

We use specifications of the following form in our hedonic price regression:

$$
L P_{i t}=\beta_{0}+\sum_{j=1}^{J} \beta_{j} L X_{i j t}+\sum_{j=1}^{J} \delta_{j} D_{i j}+\sum_{t=1}^{T} \alpha_{t} Y_{t}+\varepsilon_{i}
$$

In (16) $L P_{i t}$ represents the log of the sale price of property $i$ at time $t, t=1997-2005 . X_{i j t}$ is a vector containing $j$ continuous property characteristics of property $i$ in time $t$, and $D_{i, j}$ are $j$ binary property characteristics of property $i .{ }^{27} Y_{t}$ is a dummy variable indicating the year the property was last sold. $\beta_{0}$ is the intercept regression coefficient and $\beta_{j}, \delta_{j}$ and $\alpha_{t}$ represent the regression coefficients associated with the explanatory variables. The error term is $\varepsilon_{i}$. Note that our logarithmic form is an approximation to the nonlinearities usually involved in the solution of models such as the one presented in section 3.

\subsection{General Spatial Model}

Spatial econometric techniques are now common in estimating the determinants of property prices because of the likelihood of unobserved spatial relationships. This is because nearby properties are likely to have similar unobservable characteristics (Bell and Bockstael (2000),

\footnotetext{
26 Neighborhood attributes may include physical characteristics of the neighborhood, the socio-economic characteristics of the local residents, public service provisions, and environmental amenities.

27 The log transformation of the continuous property characteristics is consistent with past hedonic literature on housing and commercial/retail/industrial properties (Hodgson et al. (2006)). In addition, Cutter and DeWoody (2010) shows that this specification is superior for a similar data set.
} 
Ihlanfeldt and Taylor (2004)). As a result, inference based on t-statistics will be misleading. The spatial econometric literature has focused on two different types of spatial autocorrelation: spatial error dependence and spatial lag dependence (LeSage, (1999)). The first refers to the correlated errors that occur among the independent variables. It is also called spatial heteroskedasticity. It can rise from omitted variables, variable measurement error or misspecification of the functional form. The second refers to the correlated errors that occur between the dependent variables. It can be said to be spatial autocorrelation. Thus, we first estimate the joint spatial hedonic model that accounts for both types of spatial dependence:

$$
\varepsilon=\rho W_{1} L P+\lambda W_{2} e+u
$$

with this error term substituted into equation 16 we have:

$$
L P=\beta_{0}+\beta_{1} L X+\delta D+\alpha Y+\rho W_{1} L P+\lambda W_{2} e+\mu
$$

where $\rho$ measures the degree of spatial lag, $W_{1}$ is a nearest-neighbor spatial weighting matrix, $L P$ is the vector of property prices, $\lambda$ is a scalar measuring the degree of spatial correlation, $W_{2}$ is an inverse-distance weighting matrix, and $e$ and $u$ are i.i.d disturbances. If $\rho$ is significant, then the non-spatial estimate will generally be biased. Therefore, it is important to test for spatial lag. Not accounting for spatial correlation does not bias coefficients, but does result in inefficient estimation.

\subsection{Simulation Methodology}

We estimate the model of equation 16 using a Markov Chain Monte Carlo simulation methodology (the results are almost identical to the standard spatial estimate but more convenient for the simulations.) ${ }^{28}$ The method generates multiple draws $(10,000)$ of the coefficient vector and the idiosyncratic error term:

$$
\begin{aligned}
& \bar{\beta} \sim N(\hat{\beta}, \hat{T}) \\
& \bar{u} \sim N\left(0, \sigma^{2} I_{n}\right)
\end{aligned}
$$

\footnotetext{
${ }^{28}$ The results are from the sem_g estimation procedure in Jame P. LeSage’s Econometric Toolbox for Matlab, with the variance assumed homoskedastic (http://www.spatial-econometrics.com/). In Cutter (2010) we found that allowing for heteroskedastic variance does not change the key conclusions so in this paper we opt for the simpler model.
} 
The coefficients in Table 4 are the mean of these draws. The observation-specific error draw is generated by the following equation: ${ }^{29}$

$$
\bar{\varepsilon}=\left(I_{n}-\hat{\lambda} W_{2}\right)^{-1} \bar{\mu}
$$

We substitute $\bar{\beta}$ and $\bar{\varepsilon}$ into Equation 16 and calculate a predicted property price for each drawproperty attributes combination (10,000 draws). We follow the simulation procedure suggested Krinsky and Robb (1986) to estimate marginal values. First, the predicted sale price vector is estimated for each draw using this equation:

$$
\bar{P}_{i}=\varsigma \exp \left(\bar{\beta} X_{i}+\bar{\varepsilon}_{i}\right)
$$

where, $\bar{P}_{i}$ is the predicted price, $\varsigma=n^{-1} \sum_{i=1}^{n} e^{\hat{\theta}_{i}}$ is the "smearing" adjustment for transforming the $\log$ price prediction into a consistent linear price estimate, and $X=[\operatorname{Ln}(x) Y D]$ are the observed independent variables.

Next, we calculate a new matrix of independent variables based on adding a small area (denoted $\delta$ ) to either on-site parking or parcel area and we recalculate our variables, including any interaction terms. This results in a new independent variable matrix, $\tilde{X}$. Then, we calculate a new predicted price based on $\tilde{X}, \bar{\beta}$ and $\bar{\mu}$ :

$\overline{\bar{P}}_{i}=\varsigma \exp \left(\bar{\beta} \tilde{X}_{i}+\bar{\varepsilon}_{i}\right)$

Once we have (22), we calculate a vector of the price difference per change in area $\delta$ for each property:

$$
D_{i}=\frac{\overline{\bar{P}_{i}}-\overline{P_{i}}}{\delta}
$$

This is our estimate for marginal land and parking values for each property. We need to use property-by-property calculation because the estimated hedonic equation is non-linear and each property is at a different location on the hedonic surface.

With 10,000 draws from the of $\bar{\beta}$ and $\bar{\mu}$ we take the average over each $D_{i}$ vectors as the mean marginal value for the change in area for property $i$. We use this procedure to approximate the mean and distribution of marginal values for parcel area and on-site parking area.

\footnotetext{
${ }^{29}$ Our empirical testing indicates that spatial autocorrelation is negligible, therefore we estimate models where $\rho=0$ and do the simulations based on these models.
} 


\section{Minimum Parking Requirements, Data and Variables}

\subsection{Data Sets}

Parcel-level data on non-residential property sales from 1996 through 2005 over a significant portion of Los Angeles County was obtained through Costar Group, a national commercial real estate information provider (www.costar.com). We removed several types of parcels ${ }^{30}$ not suitable for the analysis and data with missing variables. In addition, we removed parcels whose characteristics indicated that they contained parking structures, including any parcels where building and parking area combined amounted to more than $110 \%$ of parcel space and any parcels where the property notes indicated underground parking or a parking structure. The remaining data fit the definition of suburban properties given in the analytical section. This means that our data may understate the impact of parking regulations because we do not include properties in denser areas where the shadow cost of parking restrictions may be higher.

The database contains the sales price of each property and a vector of structural characteristics (such as building square footage, parking lot spaces, and property code) and a vector of location characteristics (such as zip code, geographic zone, latitude, and longitude). We joined this data to information on median residential sale price by zip code for the years covered by the property sales. In order to put our parking space measure in the same units (square feet) as our other property area characteristics, we use an estimate of 350 square feet per space from a local parking expert (personal communication, Willson, 4/06/06), which includes all lanes, medians, etc., that accompany spaces. ${ }^{31}$ For robustness we also use a value of 300 square feet per space as a lower end estimate and re-estimate all specifications and simulations with that value (we do not use an upper end value because that would only strengthen the conclusions of the paper).

The initial database assigned each observation as one of three general land use types: industrial, office or retail. We divided the large number of retail properties into service,

\footnotetext{
${ }^{30}$ Parking, public facilities, residential, heavy industrial, industrial park, pleasure retail, retail-residential, retailoffice, hi-rise-office. We removed categories where there were few observations and where it was not clear how to group them with other categories. Also, we dropped observations from 1996 because there were few observations.

${ }^{31}$ The data does not allow us to test whether it is parking area or the number of parking spaces that is valued by the market. The linear transformation does not relax this constraint. By transforming the parking space variables, the regressions are using units of $1 / 350^{\text {th }}$ of a parking space, which is approximately equal to one square foot.
} 
shopping, and general retail which resulted in five broad property categories (see Table 3). ${ }^{32}$ We used Los Angeles County local roll parcel data that contains the information on every parcel within Los Angeles County with GIS location information to generate the variables used to proxy for off-site parking availability. We first matched the property sales data set to parcels in the Los Angeles County local roll data, and then used GIS techniques to identify all other parcels within a given radius of each sold parcel.

\subsection{The Variables}

The control variables $X_{i j t}$ entering equation (16) are extensive. A complete listing of the variables and their definitions are available in Table 4. Summary statistics for key variables are presented by major land-use category in Table 5. The variables generally fall into two categories: property characteristics and neighborhood characteristics. Briefly, our property characteristics include property area (pcsqft), parking area (park), total building floor area (bldg), and building age (age). All size measurements are in square feet. We expect the first three variables to have a positive marginal effect on the sale price, and building age to have a negative marginal effect.

In addition, because demand for parking may increase with building floor area, we include an interaction term between parking and building size, parkbldg. ${ }^{33}$ We expect this interaction term to have a positive coefficient as a larger building may have a higher demand and value for parking. ${ }^{34}$ With the interaction terms the marginal value of parking or total building floor area can only be calculated by taking both coefficients into account.

Also, we control for nearby parking (one-third mile radius as well) in publicly-available lots (pkgarg) and nearby parking in private, not publicly available, lots (pksup) because nearby offsite parking could be a substitute for on-site parking. ${ }^{35}$ We expect the coefficients on these

\footnotetext{
${ }^{32}$ Light industrial and industrial were combined into industrial and office-residential, office-industrial and lo-rise office into the office category. Dummy variables for these subcategories are included in all specifications.

33 This interaction is $\log ($ park)* $\log ($ bldg $)$.

${ }^{34}$ We also use dummy variables for year, property type, for four general geographic categories (Southwest Los Angeles, West San Fernando, San Gabriel, East San Fernando) and, following Ihlanfeldt and Taylor (2004), we also include a number of building construction and condition categories (see Table 4 for the categories). The full set of regression results is available on request from the authors.

${ }^{35}$ A review of walking distance literature (NJtransit (1994)) finds that most studies show that maximum walking distances are between .25 to .5 miles, with more studies in the .25 range. Therefore we chose one-third of mile as an approximation of walking distance. We also ran the same specifications with a .5 mile radius for ldens, pkgarg, pksup and found similar parameter values.
} 
variables to be positive as prices should be higher in denser areas and also higher where there is more nearby parking.

Finally, we roughly proxy for underlying land values by including the median house price in the zip code of the property (logDQprice) and total building floor area per square foot land area in a one-third mile radius (ldens). We expect the coefficients to be positive.

\section{Parking Regulation Test}

Equation (15) in the analytic model outlines the basic framework for the indirect test of parking requirements. It is likely that for some properties MPR's bind and the marginal value of additional parking spaces is less than the marginal cost of a parking space, but for other parcels MPRs do not bind:

$$
\begin{aligned}
& p_{l} \bar{l}+p_{k} \bar{K}>\frac{\partial B\left(N_{S}^{m p r}, A\right)}{\partial N_{S}} \operatorname{Lh}\left(S^{m p r}\right) \text { if MPR bind } \\
& p_{l} \bar{l}+p_{k} \bar{K}=\frac{\partial B\left(N_{S}^{m p r}, A\right)}{\partial N_{S}} \operatorname{Lh}\left(S^{m p r}\right) \text { if MPR do not bind }
\end{aligned}
$$

Properties are likely to differ in both their parking requirements and their marginal value of parking. Our estimate of the marginal value of parking and land comes from equation (23). We use a marginal cost of asphalt paving of $\$ 1.50$-a square foot. ${ }^{36}$

Our indirect test is very similar to Glaeser and Gyourko (2003) who use the gap between real estate prices and the costs of producing a marginal apartment to measure the distortions in the Manhattan housing market caused by zoning restrictions on new construction. The key idea of this approach is that in a competitive market, price will equal (minimum) average cost. In the absence of restrictions on heights or space for construction, buildings should rise to a point where the marginal cost of adding an additional floor equals the market price of the additional floor. If building higher is less profitable per square meter than building over a greater area, still we should expect the marginal cost of an extra floor to be equal to price. The gap between the observed market price and the marginal construction cost can be interpreted as a "regulatory"

\footnotetext{
${ }^{36}$ A $\$ 2.50$ average cost comes from a personal communication with Andy Youngs, California-Nevada Cement Council, 7/06/07. However a survey of ten parking-construction firms in Los Angeles we conducted found that in some cases costs are in the $\$ 1.50$ per square foot range for asphalt parking lots. We use the lower figure as it is the more conservative one in this context.
} 
tax, that is, the additional cost of space resulting from the regulation in that particular market. If the sales price of an additional floor of apartment space exceeded the marginal cost of building this additional floor then developers would have an arbitrage opportunity. Thus, Glaeser and Gyourko (2003) conclude that the difference between the price of floor space and its cost of construction must be due to some form of regulation. ${ }^{37}$

\section{Empirical Results}

The estimation results are presented in tables 6 and 7 and are briefly discussed below.

\section{Hedonic Price Models}

Equation (17a) is estimated using sale prices over the period 1997-2005. The length of this period provided a reasonable number of sales for each of the five land-use categories: industrial facilities, service retail buildings, shopping retail buildings, general retail buildings and office buildings. Therefore, we estimated specifications of each property category individually and an overall pooled model.

We estimated models with spatial error correlation, spatial error correlation and lag terms, and then with spatial error correlation and heteroskedasticity. The spatial lag coefficient was insignificant and small in all specifications and the estimated coefficients were similar to the models with spatial correlation alone. We also employed a Bayesian approach for allowing heteroskedasticity (LeSage (1999)). There is evidence of significant heteroskedasticity, but these specifications have very similar coefficients and standard errors to the specifications with spatial correlation alone. Because the spatial error correlation control appears to generate similar results as the other spatial models we tested and is less complicated, we present the spatial error correlation results. Table six reports the coefficient estimates. In addition, the table shows the values of the various test statistics and their corresponding z-values values in parenthesis.

\footnotetext{
${ }^{37}$ While this methodology rests on established microeconomic principles and is not demanding in terms of data and estimation techniques, its downside is that it does not differentiate between costs that are imposed by different aspects of regulation but is an aggregate measure of the cost of all regulatory constraints taken together: FAR restrictions, MPRs, other restrictions on land supply or even delays in decision making.
} 
The high adjusted- $R^{2}$ value (i.e. 0.83 ) is a favorable result for the model. The office, general retail and industrial equations each explain over $79 \%$ of the variation in sales prices within each of their respective categories.

The marginal effects of the property attributes are of the expected sign and generally highly significant in the pooled model (all property types). Sales prices are higher for buildings with greater property area. The coefficient on property area (lpcsqft) is positive and significant at the $1 \%$ level. The coefficient on age (lage) is negative and significant at the $1 \%$, as expected. This robust negative effect of age suggests that newness, reflecting quality, is a characteristic also valued in the non-residential market. The coefficients on each of the nearby parking measures (lpksup and lpkgarg) are significant as expected and positive at the $1 \%$ level. Also, the coefficient on IDQprice is significant and positive at the $1 \%$ level, again as expected. Finally, the Idens coefficient is positive and significant at the $1 \%$ level, indicating that, as expected, denser areas have higher property prices. The coefficients are generally consistent across the individual property-type regressions.

The coefficients on logpark, logbldg, and logparkxlogbldg need to be understood jointly since we are interested in the marginal effect of parking and building, and not so much the individual coefficients. The coefficients on logpark and logbldg are each negative and significant at the $1 \%$ level. However, the marginal effect of parking area and building area are positive over the range of the data because the interaction term logparkxlogbldg has a positive coefficient (significant at the 1\% level). It is key to include this interaction term because the analytical section predicts that parking should have a higher marginal value the larger the building floor area, ceteris paribus, and the positive coefficient on the interaction term supports this hypothesis.

\section{Parking Regulation Indirect Test}

Table 7 presents the results for our indirect test. The table has two panels: one for an average area required per parking space of 350 square feet and the other for a 300 square foot average. The results suggest that parking requirements are binding for the majority of properties. We define MPRs as binding for a given property when the estimated value of the left-hand-side (LHS) of Equation (24) is significantly greater than the right-hand-side (RHS) of Equation (24) at the 5\% level (two-sided). For all properties (row 1 ) approximately $82 \%$ of properties appear to have binding MPRs. However, this masks significant variation. Retail Shopping properties 
are estimated to have binding MPRs in only about $19 \%$ of the cases, while Service Retail properties have binding MPRs for $98 \%$ of the properties.

The scale of the social loss from MPRs is related to the difference between the RHS and LHS of Equation (24), not just whether MPRs bind. The mismatch between the costs and the marginal willingness to pay for parking area suggests that too many resources are being allocated towards the construction of parking spaces. The last two columns of Table 7 give a sense of this mismatch.

For all properties, parcel area plus construction costs are approximately $\$ 21 / \mathrm{ft}^{2}$ more than the marginal value of parking area. Suppose, for the sake of argument that the other relevant distortions in the market such as environmental externalities, congestion and parking spillover net out. Then our empirical analysis implies that the deadweight loss due to minimum parking requirements in the Los Angeles suburban properties in our dataset is in the order of \$1.5 billion (total parking sqft $(75,845,000) * \$ 21 / \mathrm{ft}^{2}$ ). The total area of properties in our data set is 1,741 acres or about 2.7 square miles, compared to 498 square miles in the City of Los Angeles alone. However, we do not know the total area in Los Angeles that could be classified as suburban commercial or industrial parking area- which is the relevant comparison for our data.

Again, there is significant variation in this difference across property types. For service retail, the parcel area is worth approximately $\$ 42 / \mathrm{ft}^{2}$ more than parking space area. This suggests that the social loss from MPRs in the service retail category is quite large (per area). Since our 1547 service retail properties have 10,287,000 sqft of surface parking this implies a deadweight loss of $\$ 488,529,630\left(10,287,000 * \$ 47.49 / \mathrm{ft}^{2}\right)$. In contrast, for industrial areas, parcel area is only worth approximately $\$ 8 / \mathrm{ft}^{2}$ more than parking space area, which implies that MPRs have comparatively low social cost per area for industrial properties. The total surface parking in the industrial category amounts to $29,376,000$ sqft, which implies a deadweight loss of \$138,654,720 $\left(29,376,000 * \$ 4.72 / \mathrm{ft}^{2}\right)$.

Our results thus suggest that reducing parking standards for general retail, service retail and office uses will be a successful strategy in encouraging new development to provide fewer parking space on average. In contrast, this strategy will be less successful for shopping retail and 
industrial uses, which seem to either have lower standards relative to demand or be less sensitive to minimum parking standards. ${ }^{38}$

The estimated mean marginal land values used to calculate parking costs are somewhat lower than the per square foot land values in the Los Angeles area for vacant land. An analysis (Cutter et al. (2008)) shows the value of vacant land zone industrial averaged $\$ 38 \mathrm{ft}^{2}$ and vacant land zoned commercial averaged $\$ 98 / \mathrm{ft}^{2}$. Because vacant land may not be representative of land values overall, we do not expect the marginal value of land to exactly equal the value of vacant land. However, the analysis of vacant land prices suggests that our land values are conservative and therefore our indirect test of whether MPRs bind is conservative. ${ }^{39}$

If minimum parking requirements force developers to supply parking beyond what the market is willing to pay for, then profit-maximizing developers will try to mitigate the negative effect from parking provisions on profits by economizing for example in space with more compact spots, narrower aisles, and other measures to minimize paved area. In this setting, the $350 \mathrm{ft}^{2}$ parking size estimate would be too large for some property types. Therefore, we have also re-estimated the models and simulations using a $300 \mathrm{ft}^{2}$ estimate to test the robustness of the results. This is a low-end estimate of the total area per parking space that could be achieved with Los Angeles area parking regulations. In general, the difference between the total parking costs and parking values narrows but not substantially. The estimated percentage of properties where the MPRs bind fall by three percentage points to 79 percent for all properties. Even in this low parking space size scenario it appears that MPRs bind for a large majority of properties.

\section{Conclusions}

Minimum parking regulation is a pervasive feature of United States land-use practices. Davidson et al. (2002) state that parking planning questions are among the top five queries for the American planning service each year. Authors such as Shoup (1999), Willson (1995) and Davidson et al. (2002) have suggested that parking regulation forces developers to place far more

\footnotetext{
${ }^{38}$ For instance large shopping retail tends to want a lot of spaces to deal with the Christmas Rush.

${ }^{39}$ One curious result from these regressions is the negative marginal value accorded to parking area in the service retail category. A negative marginal value is plausible if the MPRs are so high that additional parking area adds no value to the lot and there are significant expenses for cleaning, maintenance, and occasional replacement of the parking lot. The negative $\$ 8.69 / \mathrm{ft}^{2}$ marginal value could be accounted for by a maintenance and upkeep cost of $\$ .78 / \mathrm{ft}^{2}$ per year. This is plausible since asphalt must be replaced every $10-15$ years at a cost of $\$ 2-\$ 3 / \mathrm{ft}^{2}$, and periodic maintenance and cleaning is required by water quality regulators for many of these properties.
} 
parking spots than necessary on their lot. Arnold and Gibbons (1996) detail the destructive environmental effects of excessive impermeable surfaces. Shoup (1999) also suggests that parking regulations may have a dynamic effect where the design requirements of large parking areas render new development pedestrian unfriendly so that more individuals are forced to travel by car.

However, to our knowledge, the evidence that parking requirements increase the amount of parking spaces built is limited to a few case studies. This paper seeks to remedy that by examining whether there is evidence of a parking regulation effect for sold properties in Los Angeles County.

Our analytical results show that when MPRs bind, the excess parking results in a deficit for the developer of a new building. This induced deficit constitutes an indirect tax on building square footage. As a result, this creates a disincentive to high-density development because it imposes an extra wedge between the marginal revenue gain from additional building square footage and the marginal construction costs. Since the marginal cost of providing more parking spaces at a site usually increases dramatically for underground structures, this parking tax is also higher for larger buildings.

Our analytical model of optimal development of a parcel also implies that the marginal value of parking should be less (equal) to the marginal value of land for a parcel plus the construction cost of parking in the presence (absence) of binding minimum parking regulations. We test this proposition for a multi-year dataset of sales and for six different property types using a spatial error model. We find that for the majority of properties a null hypothesis of equality between marginal parking and marginal land plus construction costs is rejected at a 5\% significance level. This supports the idea that minimum parking requirements significantly affect the amount of parking on a parcel. The magnitudes of the differences in the marginal quantities suggest that parking minimum requirements have large effects on the distribution of parcel space between various uses. Further research should examine the quantitative impact of parking minimums on the aggregate amount of parking and impervious space.

If the goal of minimum parking requirements is to prevent parking spillover and traffic congestion associated with cruising for on-street parking, our results suggest that MPRs are a blunt and inefficient form of parking management. Other forms of parking pricing that accounts for social externalities can be a superior parking management (Small (1992), Shoup (2004, 
2005), Arnott et al. (2005)). For example, Arnott et al. (2005) show that an efficient on-street parking pricing scheme can produce travel time savings from reducing traffic congestion and wasteful cruising-for-parking activity and at the same time raise government revenues which can be used to reduce distortionary taxation. ${ }^{40}$

This research provides thus further evidence for the arguments of Shoup (1999) and Willson (1995) that parking minimums significantly distort land-use decisions. In addition, the evidence that, in some cases, parking use value is a small fraction of parcel land value suggests that the efficiency losses from parking minimums may be quite large. However, a full consideration of the optimal level of off-street parking would have to consider the congestion externalities due to lower requirements as well as the environmental benefits of less parking.

\section{Acknowledgements}

For insightful comments and suggestions we are grateful to Richard Arnott, Jan Brueckner and Jos Van Ommeren. We also thank the participants at the Kuhmo Nectar Conference on Transport Economics 2010 and Summer School, at the $10^{\text {th }}$ Meeting of Society for Social Choice and Welfare 2010 and at the IV Congreso de la Asociasion Hispano-Portuguesa de los Recursos Naturales Y Ambientales (AERNA) for their helpful comments. Any shortcomings in the paper are ours alone.

\footnotetext{
${ }^{40}$ Arnott et al. (2005) also emphasize the need to examine policies that might complement congestion pricing, such as appropriately pricing freight and mass transit; staggering work hours for government employees; encouraging biking and walking; and improving the design of roads and intersections to improve traffic flow. Small (1992) discusses the design of a package of congestion charges and revenue uses that may be more politically feasible and thus, look attractive to most people. The author also discusses the potential amounts and uses of money raised by congestion pricing on all congested freeways and arterials in the five-county Los Angeles region. His numerical calculations of the effects of this package on various individuals confirm that such a package can create net benefits for a wide spectrum of individuals and interest groups.
} 


\section{Reference List}

Akbari, H., M. Pomerantz, and H. Taha. (2001). "Cool surfaces and shade trees to reduce energy use and improve air quality in urban areas" Solar Energy 70(3):295-310.

Arnold, C. L. and C. J. Gibbons (1996). "Impervious surface coverage - The emergence of a key environmental indicator." Journal of the American Planning Association 62(2): 243-258.

Arnott, R.J., Tilmann Rave, and Ronnie Schob (2005). Alleviating Urban traffic Congestion. Cambridge, Mass: MIT Press.

Arnott, R.J., MacKinnon, J.G., (1977). "Measuring the costs of height restrictions with a general equilibrium model.” Regional Science and Urban Economics 7: 359-375.

Bento, A. M., S. F. Franco, et al. (2006). "The efficiency and distributional impacts of alternative anti-sprawl policies." Journal of Urban Economics 59 (1): 121-141.

Bell, K. P. and N. E. Bockstael (2000). "Applying the generalized-moments estimation approach to spatial problems involving micro level data." Review of Economics and Statistics 82(1): 7282.

Bollinger, C. R., K. R. Ihlanfeldt, et al. (1998). "Spatial variation in office rents within the Atlanta region." Urban Studies 35(7): 1097-1118.

Bertaud, A. and J.K. Brueckner (2005), "Analyzing building height restrictions: predicted impacts and welfare costs.” Regional Science and Urban Economics 35 (2): 109-125.

Brueckner, J. K. (2000). "Urban sprawl: Diagnosis and remedies." International Regional Science Review 23(2): 160-171.

Clapp, J.M. (1980). "The intrametropolitan location of office activities.” Journal of Regional Science 20: 387-399.

Colwell, P. F., H. J. Munneke, et al. (1998). "Chicago's office market: Price indices, location and time." Real Estate Economics 26(1): 83-106.

Cunningham, C.R. (2006). "House Price Uncertainty, Timimg of Development and Vacant Land Prices: Evidence for real options in Seatle.” Journal of Urban Economics 59: 1-31.

Cutter, W. B., K. A. Baerenklau, et al. (2008). "Costs and benefits of capturing urban runoff with competitive bidding for decentralized best management practices." Water Resources Research 44 (9).

Cutter, W. B., DeWoody, A. (2010). "Parking Externalities in Commercial Real Estate." Real Estate Economics, 38 (2): 197-223. 
Davidson, M., F. Dolnick, et al. (2002). Parking standards. Chicago, IL, American Planning Association, Planning Advisory Service.

Feitelson, E. and O. Rotem (2004). "The case for taxing surface parking." Transportation Research Part D-Transport and Environment 9(4): 319-333.

Ferguson, B. K. (2005). Porous pavements. Boca Raton, Fla., Taylor \& Francis.

Glaeser, E. L. and J. Gyourko (2003). "The Impact of Building Restrictions on Housing Affordability." Economic Policy Review 9(2): 21-39.

Glaeser, E. L. and J. Gyourko (2005). "Urban Decline and Durable Housing." Journal of Political Economy 113: 345-75.

Deily, M. and W. B. Gray (1991). "Enforcement of Pollution Regulations in a Declining Industry. Journal of Environmental Economics and Management 21: 260-274.

Grenadier,S.R. (1996). "The Strategic Exercise of Options: Development Cascades and Overbuilding in Real Estate Markets.” Journal of Finance 51 (5): 1653-79.

Hodgson, D. J., B. A. Slade, et al. (2006). "Constructing commercial indices: A semiparametric adaptive estimator approach." Journal of Real Estate Finance and Economics 32 (2): 151-168.

Holland, A.S., S.H. Ott, and T.J. Riddiough, (2000). "The Role of Uncertainty in Investment: An Examination of Competing Investment Models Using Commercial Real Estate Data.” Real Estate Economics 28: 33-64.

Hunnicutt, J. (1982). Parking, Loading, and Terminal Facilities. Transportation and Traffic Engineering Handbook. I. o. T. Engineering, Prentice Hall.

Ihlanfeldt, K. R. and L. O. Taylor (2004). "Externality effects of small-scale hazardous waste sites: evidence from urban commercial property markets." Journal of Environmental Economics and Management 47(1): 117-139.

Institute of Transportation Engineers. (1985). Parking generation. Washington, D.C., USA, Institute of Transportation Engineers.

Krinsky, I. and A. L. Robb (1986). "On approximating the statistical properties of elasticities." Review of Economics and Statistics 68(4): 715-719.

Manville, M. and D. Shoup (2005). "Parking, people, and cities." Journal of Urban Planning and Development-Asce 131(4): 233-245.

Mukhija V., and D. Shoup, (2006). "Quantity Versus Quality in Off-Street Parking Requirements.” Journal of the American Planning Association 72 (3): 296-308. 
NJ Transit. (1994). Planning for transit-friendly land use: A handbook for New Jersey communities. Trenton, NJ: NJ Transit.

LeSage, J. P. (1999), Applied Econometrics using MATLAB.

Shoup, D. C. (1999). "In lieu of required parking." Journal of Planning Education and Research 18(4): 307-320.

Shoup, D. C. (1999). "The trouble with minimum parking requirements." Transportation Research Part a-Policy and Practice 33(7-8): 549-574.

Shoup, D. C. (2004). "The ideal source of local public revenue." Regional Science and Urban Economics 34(6): 753-784.

Shoup, D. C. (2005). The high cost of free parking. Chicago, Planners Press, American Planning Association.

Shoup, D. C. and D. H. Pickrell (1978). "Problems With Parking Requirements In Zoning Ordinances." Traffic Quarterly 32(4): 545-561.

Sivitanidou, R. (1995). "Urban Spatial Variations In Office-Commercial Rents - The Role Of Spatial Amenities And Commercial Zoning." Journal of Urban Economics 38(1): 23-49.

Sivitanidou, R. (1996). "Do Office-Commercial Firms Value Access to Service Employment Centers? A Hedonic Value Analysis within Polycentric Los Angeles.” Journal of Urban Economics 40: 125-149.

Sivitanidou R, Wheaton W C, (1992). "Wage and Rent Capitalization in the Commercial Real Estate Market" Journal of Urban Economics 31: 206-229.

Sivitanidou, R. and P. Sivitanides (2000). "Does the Theory of Irreversible Investments Help Explain Movements in Office-Commercial Real Estate?” Real Estate Economics 28 (4): 623662.

Small, K.A. (1992). “using the revenues from congestion pricing.” Transportation 19: 359-381.

Taha, H. (2008a). "Urban surface modification as a potential ozone air-quality improvement strategy in California: A Mesoscale modeling study." Boundary-Layer Meteorology 127 (2): 219-239.

Taha, H. (2008b). "Meso-urban meteorological and photochemical modeling of heat island mitigation." Atmospheric Environment 42 (38) :8795-8809.

U.S. Environmental Protection Agency, Urban and Economic Development Division (“EPA”) (1999). Parking Alternatives: Making Way for Urban Infill and Brownfield Development. Washington, D.C.: U.S. Environmental Protection Agency. 
U.S. Environmental Protection Agency, Urban and Economic Development Division ("EPA") (2008). Green Parking Lot Resource Guide. Washington, D.C.: U.S. Environmental Protection Agency.

Willson, R. W. (1995). "Suburban Parking Requirements - A Tacit Policy For Automobile Use And Sprawl." Journal of the American Planning Association 61(1): 29-42. 